\title{
Measuring land losses caused by water erosion using the SWAT model in the Ourika watershed in the High Atlas of Morocco
}

\author{
Meysara Elmalki ${ }^{1,2, *}$, Fouad Mounir ${ }^{3}$, Abdellah Ichen ${ }^{4}$, Taoufiq Qaini ${ }^{5}$, Thami Khai $^{1}$, and Mohammed Aarab ${ }^{1}$ \\ ${ }^{1}$ Faculty of Sciences, Moulay Ismail University, 11201 Meknes, Morocco \\ ${ }^{2}$ Forests and Water Department, 10090 Rabat, Morocco \\ ${ }^{3}$ National Forest Engineering School, 511 Salé, Morocco \\ ${ }^{4}$ Faculty of Sciences, Mohammed V University in Rabat, 1014 Rabat, Morocco \\ ${ }^{5}$ Study office TTOBA, 10080 Rabat, Morocco
}

\begin{abstract}
In Morocco, the phenomena of water erosion cause significant economic losses mainly linked to the silting up of dams, the degradation of equipment and socio-economic infrastructures, the loss of soil productivity and the insecurity of the population. The SWAT (Soil and Water Assessment Tool) model was used to estimate the quantities of sediments generated by the various erosive processes at the level of the Ourika watershed. The SWAT modeling, which is done with daily time steps, used as basic data; a Digital Elevation Model GDEM-ASTER (Global Digital Elevation-Advanced Space borne Thermal Emission and Reflection Radiometer) with $30 \mathrm{~m}$ of resolution, a land cover map developed from the Landsat 8 OLI (Operational Land Imager) satellite image of 2017 with $30 \mathrm{~m}$ of resolution and a soil map published by FAO (Harmonized World Soil Database). Also, daily meteorological data from the Tensift Water Basin Agency over a period from 1992 to 2001 were used. The results obtained showed that soil losses due to water erosion in the Ourika watershed reached an average of 9.18 t.ha-1.year-1. The model was calibrated and validated using the SWAT-CUP (SWAT Calibration and Uncertainty Procedures) software SUFI-2 (Sequential Uncertainty Fitting) and after several simulations and iterations a determination coefficient R2 of 0.76 was obtained.
\end{abstract}

\section{Introduction}

Water erosion is a phenomenon that manifests itself through the degradation of land by rainwater runoff and causes significant economic losses, mainly linked to the silting up of dams (loss of $1.7 \mathrm{MM} \mathrm{m} \mathrm{m}^{3}$ of storage capacity since 1950 [1]), the degradation of equipment and socio-economic infrastructures, the loss of soil productivity and the insecurity of the population. In Morocco, sedimentation surveys carried out in six reservoirs in various watersheds revealed that erosion varies from 2 to 59 t.ha $^{-1}$.year ${ }^{-1}$ [2]. Indeed, the very high climate variability characterized by frequent periods of drought and heavy rainfall, the presence of highly erodible soils due to their weak structure, lack of depth and absence of organic matter, the uneven relief with steep slopes and very diverse landscapes, these findings constitute the main physical factors influencing soil erosion processes. Thus, the quantification and mapping of erosion are fundamental tools to know the distribution and geographical extent of the phenomenon, thanks to these tools it is possible to incorporate this phenomenon as a factor in the process of land use planning, and more particularly in the process of integrated management of mountain areas. Different approaches can be considered to assess and quantify land losses. Some are based on expertise (choice by the expert of the parameters and weighting to be applied), others on modelling (empirical or physical, global or spatialized, deterministic or statistical model). The purpose of this study is to evaluate annual soil losses using the SWAT (Soil and Water Assessment Tool) model, a model developed by [3] for the American Department of Agriculture (USDA), the SWAT model makes it possible to integrate climatic, hydrological and biological data as well as complex phenomena such as erosion, infiltration and agricultural practices. It should be noted that this work was conducted on ArcSWAT, which is a combination of the SWAT model and the ArcGIS graphical user interface.

\section{Material and methods}

\subsection{Study area}

The Ourika watershed covers an area of $573.02 \mathrm{Km}^{2}$, between latitudes $31^{\circ} 22^{\prime} 25.60^{\prime \prime}$ and $31^{\circ} 3^{\prime} 0.59^{\prime \prime}$ North and longitudes $7^{\circ} 44^{\prime} 51.76^{\prime \prime}$ and $7^{\circ} 47^{\prime} 49.50^{\prime \prime}$ East, it is an integral part of the great basin of Tensif, located straddling the Ourika and Rheraya forests, bounded to the North by the Haouz plain, to the South by the high

\footnotetext{
* Corresponding author: elmalki.meysara@gmail.com
} 
basin of Souss wadi, to the East by the watershed of Oued Zat and to the West by the watersheds of the Rherari and Isli wadis. From the geological point of view, the Ourika valley is located at the level of the Western High Atlas. This structural unit also called Atlas of Marrakech, is famous for its peaks exceeding $4000 \mathrm{~m}$ of altitude; it is composed of Precambrian magmatic basement and covered with triassic sedimentary series of seltites, red sandstones and basalts. The axial zone of this chain, which corresponds to the high peaks, is formed of metamorphic, plutonic and volcanic rocks. Thus, the Ourika basin, is precisely located on the northern flank of the Atlas of Marrakech and presents, of general direction ENE-WSW, four structural units separated by major accidents, it is the North to South of the Haouz zone, the zone of the fore-mountains, the zone of the high plateaus and the axial zone. The lithological nature of the substrates gives rise to different types of soil. Four types of bedrock can be distinguished in the zone: Soils on eruptive rock, Soils on shisto-sandstone fylsch, Soils on permo-triassic red sandstone and marl formations and Soils on limestone [4]. Several signs of aridity place the Ourika Valley in a semi-arid zone with a sub-humid tendency, where oceanic (disturbances coming from the west), continental and mountain influences interfere (Fig. 1).

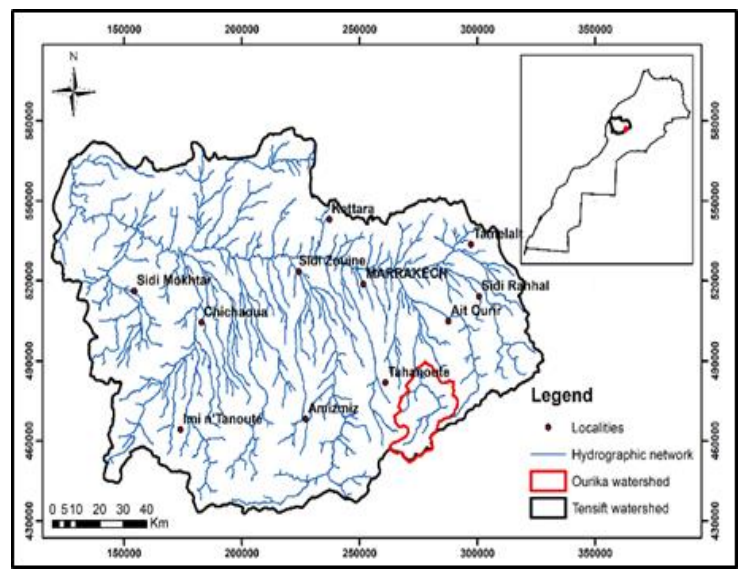

Fig. 1. Situation map of the Ourika watershed.

The rainfall and hydrological regimes of the Ourika are characterized by high Spring water. The maximum rainfall is generally recorded in March and April, while the peak hydrological, more individualized, is recorded in April alone [5]. The Ourika watershed is marked by a great spatio-temporal climatic variability. Annual precipitation averages $500 \mathrm{~mm}$, it increases with altitude and it goes from $400 \mathrm{~mm}$ in the foothills while exceeding $700 \mathrm{~mm}$ on the high peaks of the watershed. Average temperatures range from 21.5 to $32^{\circ} \mathrm{C}$ and 4 to $5.7^{\circ} \mathrm{C}$ for maxima and minima respectively. The hottest period of the year is recorded during the months of July and August, while the coldest period is marked for the months of December and January, so the temperature varies from $-7.2{ }^{\circ} \mathrm{C}$ to $48.2{ }^{\circ} \mathrm{C}$, with an average of 27.8 ${ }^{\circ} \mathrm{C}$ [6]. The different plant formations of the Ourika watershed are diversified, we find tree, shrub, bush and non-forest landscapes formations.

\subsection{Methodology}

The SWAT model is based on the physical processes at work in the watershed. Its great robustness and efficiency make it a model widely used in the field of watershed modelling, notably by various US federal agencies or the European Commission [7]. This model works with fine spatial and temporal units. With a daily temporal resolution, and a spatial resolution corresponds to a Hydrological Response Unit (HRU). The HRUs are geographical units considered homogeneous from the water, pedoclimatic and land use point of view [7]. These HRUs are not spatialized but are distributed within sub-basins that are. These sub-basins divide the catchment area into river segments. It is at the scale of these units that the model calculations are carried out. As this model is integrated in ArcGIS (Environmental Systems Research Institute), it allows spatialized information management. At the output of the model, it is possible to retrieve information on different time and space scales [8]. The establishment of the hydrological balance by SWAT, uses the state of land use, soil characteristics, slope and climatic data, adding to this a digital terrain model for the delimitation of the watershed and hydrological networks.

Soil and Water Assessment tool (SWAT) is a hydrological model to assess sediment, impact of land use, in-stream water quality, climate change and, water quality and quantity variation. SWAT can determine as well as river basin scale, continuous-time model that operates on a daily or sub-daily time step, computationally efficient, and able to estimate long-term yields in large watersheds. The model is physicallybased and uses readily available temporal and spatial data. The hydrological cycle is simulated by SWAT model according to the equation below of water balance [9].

$$
S W t=S W 0+\sum_{n-1}^{t}(R d a y-Q \operatorname{surf}-E a-W \text { seep }
$$

Where $\mathrm{SW}_{\mathrm{t}}$ is the soil water content $(\mathrm{mm}), \mathrm{SW}_{0}$ is the water available to plants $(\mathrm{mm}), \mathrm{R}_{\text {day }}$ is the precipitation $(\mathrm{mm}), \mathrm{Q}_{\text {surf }}$ is the surface runoff $(\mathrm{mm}), \mathrm{E}_{\mathrm{a}}$ is the evapotranspiration $(\mathrm{mm}), \mathrm{W}_{\text {seep }}$ is the percolation $(\mathrm{mm})$, $\mathrm{Q}_{\mathrm{gw}}$ is the low flow (mm) and $\mathrm{t}$ is the time (day).

The SWAT-CUP tool (SWAT Calibration and Uncertainty Procedures) is a program to perform calibration, validation and sensitivity analysis of the SWAT model. This tool also allows to run the model a large number of times by varying one or more parameters. This program then automatically compares the simulations by calculating their $\mathrm{R}^{2}$ values (coefficient of determination) and suggests a value of parameter that maximizes the performance criteria. It also produces a hydrograph that allows to see the consequences of the modification of this parameter on the flows. The variation of the parameters is done between two bounds, representing either absolute values of the parameter, i.e. percentages of the initial value. These user-defined variation limits allow you to stay 
within a consistent range of values for a parameter given [10].

\subsubsection{Digital elevation model and Slope map}

The Digital Elevation Model (DEM) used is the GDEM-ASTER (Global Digital Elevation-Advanced Space borne Thermal Emission and Reflection Radiometer) with a spatial resolution of $30 \mathrm{~m}$, it was extracted from ASTER satellite images through the stereoscopy process. It allows the derivation of basin physiographic characteristics such as basin, sub-basin boundaries and slope, hydrographic network and river hierarchy, using GIS tools on the ArcGIS interface (Fig. 2, Fig. 3 and Fig. 4).

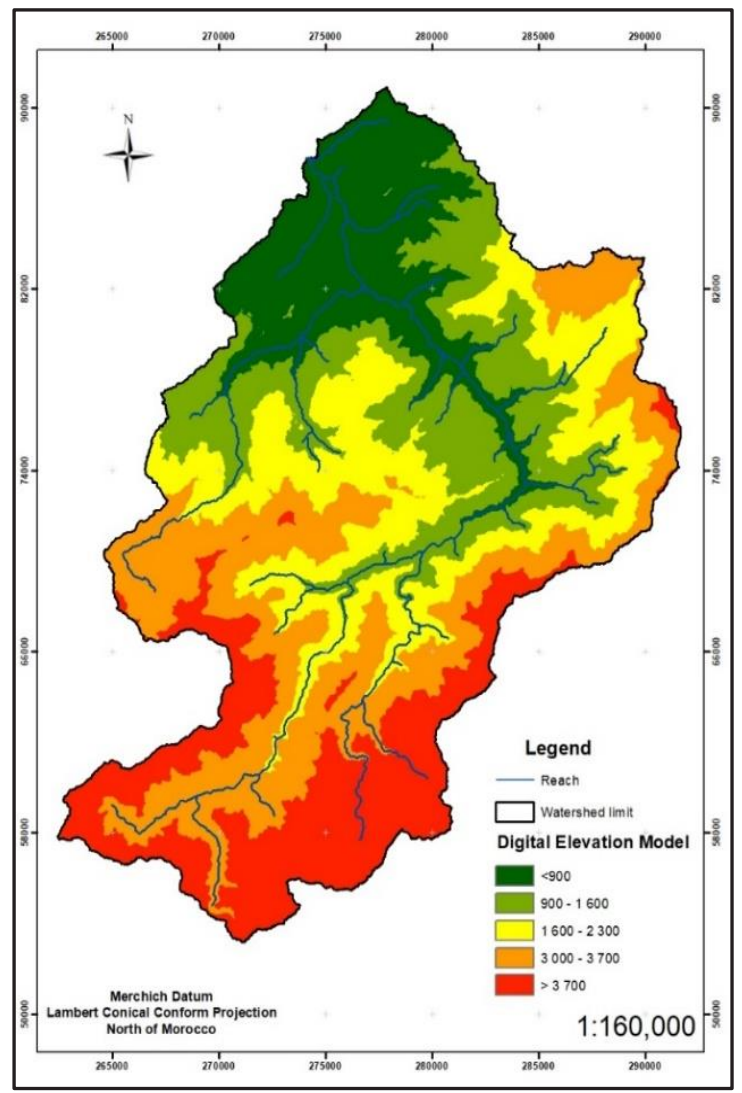

Fig. 2. Digital elevation model map of the Ourika watershed.

The slope classes derived from the digital elevation model are divided into 4 categories, defined as follows; extreme slopes with 44547 ha or $78 \%$ of the total area, steep slopes with 8860 ha or $15 \%$ ha, moderate slopes with 3368 ha or $6 \%$, low slopes with 527 ha or $1 \%$ (Fig. 3).

The digital elevation model allowed us to delimit the Ourika watershed into 69 sub-basins and 197 hydrological response units from the main and secondary outlets. This spatial discretization into sub units corresponds to the combination of a sub-basin of a soil type and a type of occupation whose parameters will influence the phases of the water balance. A HRU (Hydrological Response Unit) therefore has its own homogeneous hydrological behaviour, the various flows are therefore calculated on the basis of this unit and then summed up to provide an overall value for the basin outlet (Fig. 4).

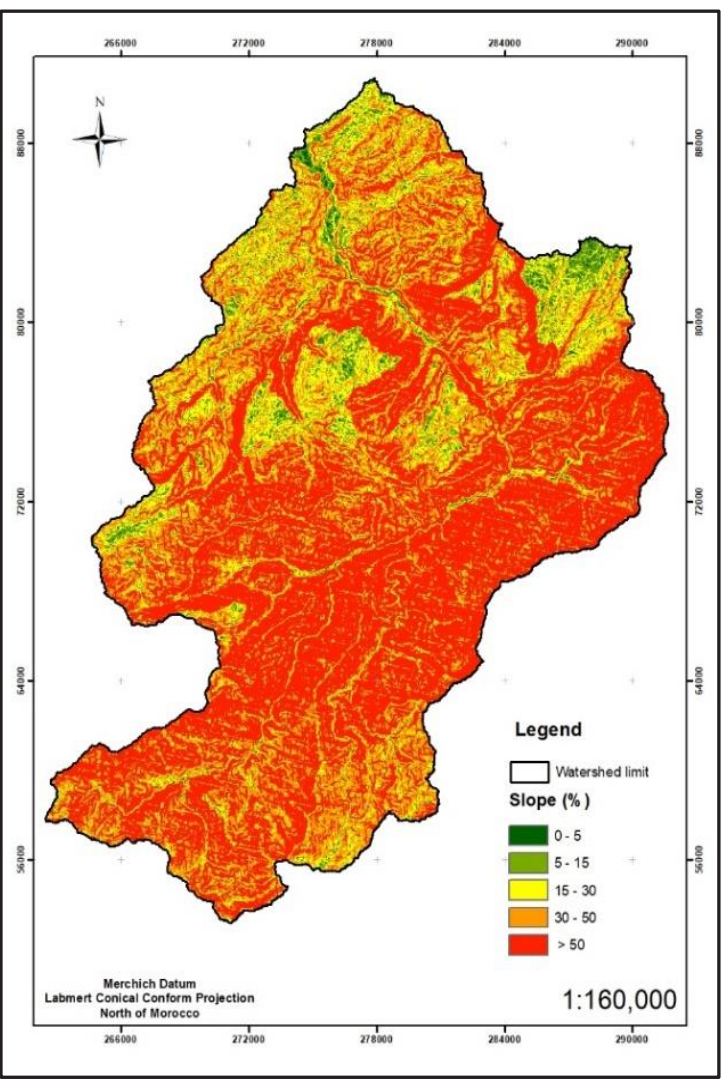

Fig. 3. Slope map of the Ourika watershed.

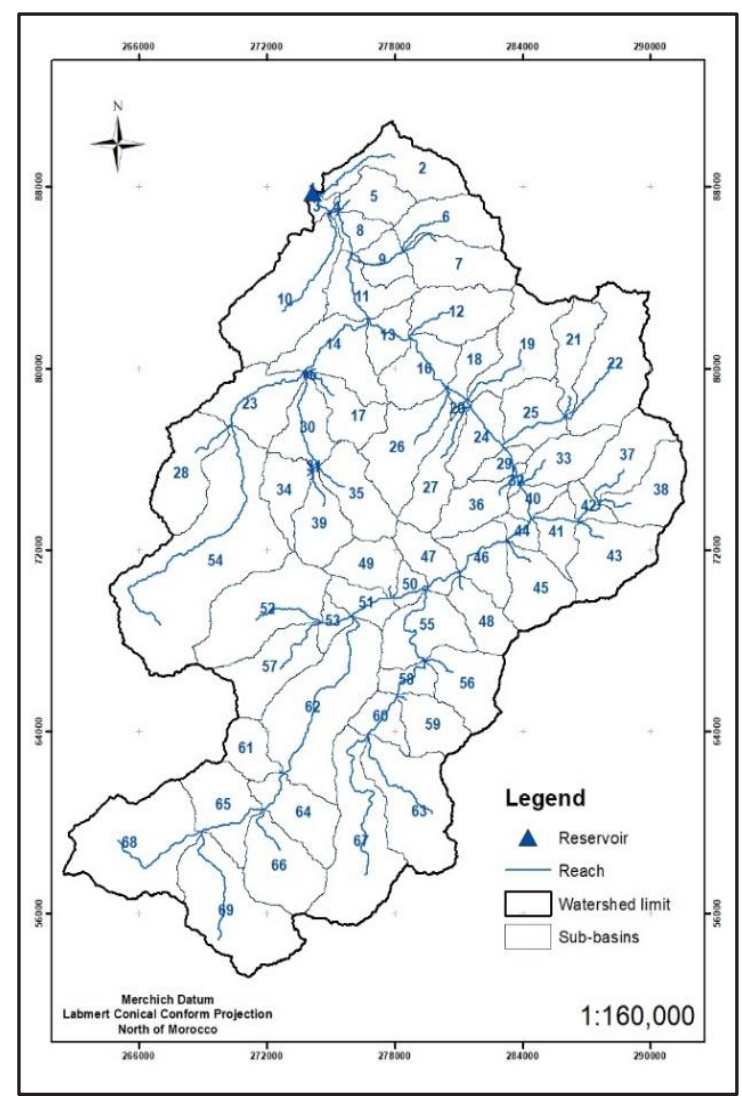

Fig. 4. Hydrographic network and sub-basin map of the Ourika watershed 


\subsubsection{Land use map}

The land use map was produced from the Landsat 8 OLI satellite image of the year 2017, with a resolution of 30 m, a SVM (Support Vector Machine) supervised classification was adopted to have the different land use classes in the study area.

Figure 5 shows that the land use classes are distributed as follows; Forest 8610 ha or $15 \%$, arboriculture with 2988 ha or $5 \%$, rangeland with 11 333 ha or $20 \%$, bare land with 33525 ha or $58 \%$, buildings with 759 ha or $1.74 \%$ and water with 87 ha or $0.16 \%$.

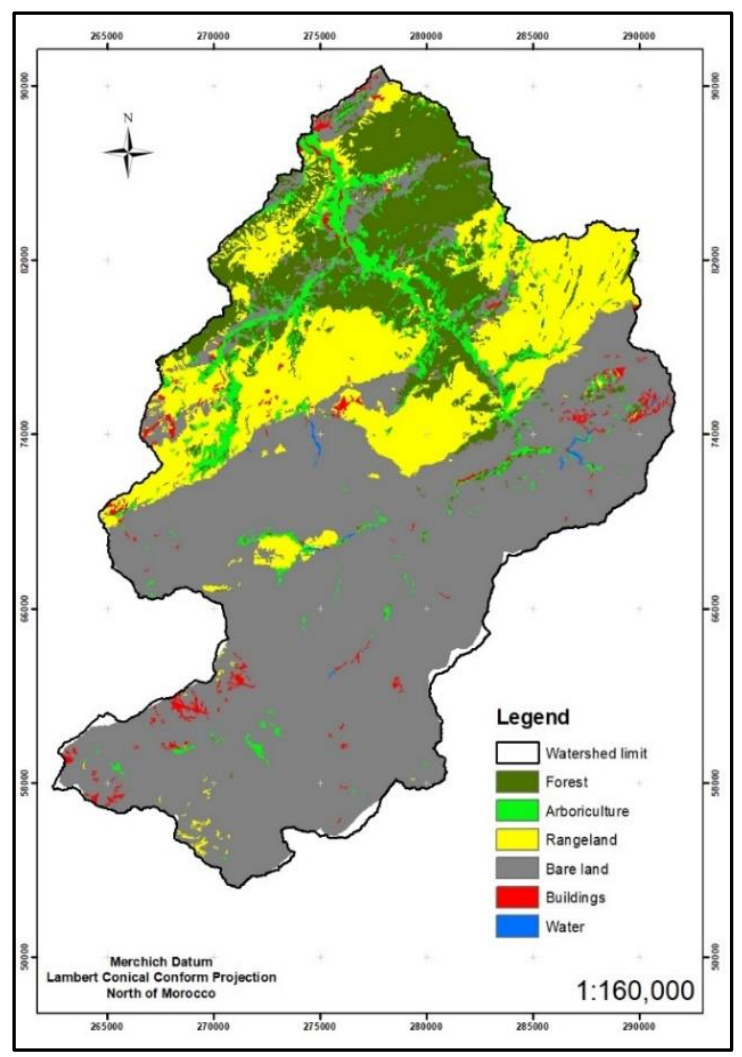

Fig. 5. Land use map of the Ourika watershed.

\subsubsection{Soil map}

The soil map was obtained from the Harmonized World Soil Database (HWSD), developed by the Food and Agriculture Organization of the United State (FAO) [11]. The soil map of Africa was based on the 1:5,000,000 topographic background of the American Geographical Society (Fig. 6).

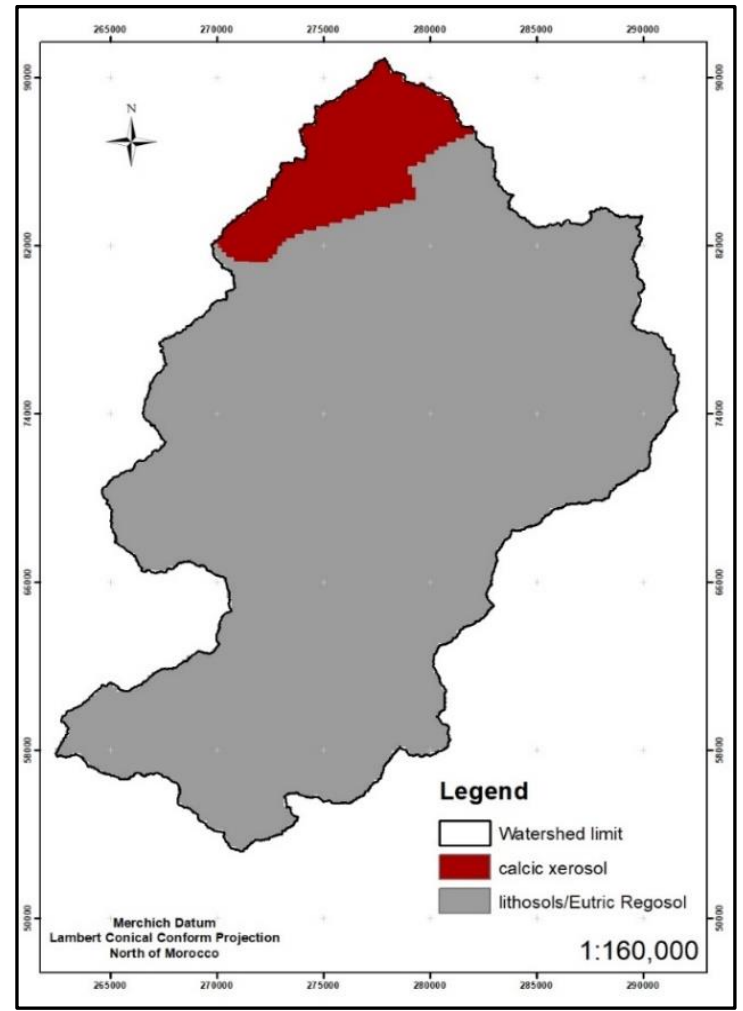

Fig .6. Soil map of the Ourika watershed.

From a soil point of view, the study area is covered by two soil types according to the World Soil Map of FAO. These are Calcic Xerosols; which are soils subject to an arid regime, with a weakly developed ochric A horizon, not having a high salinity with a calcium horizon at minus $125 \mathrm{~cm}$ depth and no clay horizon overlying the calcium horizon. Then, Lithosols, which are limited in depth by a coherent, hard and continuous rock at less than $10 \mathrm{~cm}$ depth and finally Eutric Regosols; which are formed on unconsolidated materials, excluding recent alluvial deposits, having no diagnostic horizons. With a base saturation rate of $50 \%$ or more at least between 20 and $50 \mathrm{~cm}$ from the surface, but which are not limestone at the same depth, having no permafrost less than $200 \mathrm{~cm}$ deep (Fig. 6).

\subsubsection{Climate data}

Daily rainfall from 4 stations; two inside and two outside the study area were used, these data were collected from the Tensift Water Basin Agency over the period 19922001 (10 years) (Table 1).

Table 1. Climate stations of the Ourika watershed.

\begin{tabular}{|c|c|c|c|}
\hline Station name & Latitude & Longitude & Altitude (m) \\
\hline Aghbalou & 31.317 & -7.749 & 1070 \\
\hline Marrakech & 31.555 & -8.031 & 460 \\
\hline Taferiat & 31.541 & -7.596 & 760 \\
\hline Tahnaout & 31.289 & -7.961 & 925 \\
\hline
\end{tabular}




\section{Results and discussion}

In the present study, a period of observation of climate data for the 4 stations from 1992 to 2001 was chosen with the preparation of the digital elevation model, the land use map and the soil map in the study area. These data were integrated into the SWAT database after having edited them as well as files read and executed by SWAT program. The collection of the data and their integration into the SWAT model made it possible to quantify land losses in a preliminary way.

\subsection{Model calibration and validation}

The model was calibrated and validated using the SUFI2 program integrated in the SWAT-CUP software, this operation consisted in using real data on the daily flows of the Aghbalou station for the year 2002 as the flow data were not available before the year 2001, these data were collected from the Tensift Water Basin Agency. They are compared with the data simulated by the model in order to find an adequate correlation. The validation was done using the same parameter (daily flow), for the same station and year.

In a first step, 28 parameters were used to determine which of these parameters showed a high sensitivity to the indicator used (daily flow) in the Ourika watershed, after 3 iterations of 200 simulations, only 9 parameters showed a high sensitivity to the daily flow as shown in Table 2; saturated hydraulic conductivity (SOL_K), slope length for lateral subsurface flow (SLSOIL), maximum canopy storage (CANMX), threshold depth of water in the shallow aquifer for "revap" or percolation to the deep aquifer to occur (REVAPMN), moist soil albedo (SOL_ALB), groundwater delay time (GW_DELAY), available water capacity of the soil layer (SOL_AWC), depth from soil surface to bottom of layer
(SOL_Z), initial SCS runoff curve number for moisture condition II (CN2).

The model calibration consists in refining the information entered in the model and adapting the parameters to the particular context of the Ourika watershed. This operation was carried out using semiautomatic tools such as SWAT-CUP. Model validation is carried out by comparing the outputs of the parameterized model with the actual data recorded in the Ourika watershed.

To evaluate the performance of the model, the most relevant methods are: graphical interpretation (comparison of real and simulated hydrographs) and calculation of coefficients characterising the gap between the model and reality, such as the NashSutcliffe efficiency coefficient (NSE), the coefficient of determination $\left(\mathrm{R}^{2}\right)$ and the percentage bias (PBIAS) [12, 13, 14]. Many other indicators are used by different authors, each with its own strengths and weaknesses. It is therefore necessary to choose the indicator that best suits the situation under consideration. For example, NSE should be avoided if flows are close to zero because even for a very small change in flow it will be very negative [15]. Conversely, the calculation of the model bias (MBIAS) masks flow variations but is very sensitive at low flow rates [16]. The root mean square error (RMSE) does not account for errors in the observed data, so the NSE should be preferred if the data are imperfect.

Since our study area did not record any high flows during the study period, it was considered useful to determine the coefficient of determination $\left(\mathrm{R}^{2}\right)$ to calculate the performance of the model used, which was of the order of 0.76 after calibration and validation (Fig. 7 and Fig. 8), which means that there is a strong correlation between the simulated daily flows and those measured on the field [17], and that the model is adapted to the Ourika watershed through its calibration and validation.

Table 2. Most sensitive parameters after calibration by SUFI-2.

\begin{tabular}{|c|c|c|c|c|}
\hline Parameter Name & Rank & Fitted Value & Min Value & Max Value \\
\hline R_SOL_K(..).sol & 1 & 0.139 & -0.005 & 0.157 \\
\hline V_SLSOIL.hru & 2 & 137.429 & 112.115 & 152.780 \\
\hline V_CANMX.hru & 3 & -3.368 & -6.622 & -0.081 \\
\hline V_REVAPMN.gw & 4 & 23.104 & 8.223 & -0.251 \\
\hline R_SOL_ALB(..).sol & 5 & -0.271 & -0.301 & 240.210 \\
\hline V_GW_DELAY.gw & 6 & 140.748 & 131.805 & -0.153 \\
\hline R_SOL_AWC(..).sol & 7 & -0.195 & -0.228 & 0.462 \\
\hline R_SOL_Z(.).sol & 8 & 0.392 & 0.324 & -0.591 \\
\hline R_CN2.mgt & 9 & -0.667 & -0.716 & \\
\hline
\end{tabular}

$\mathrm{V}$ : means the existing parameter value is to be replaced by a given value;

$\mathrm{R}$ : means an existing parameter value is multiplied by (1+ a given value). 


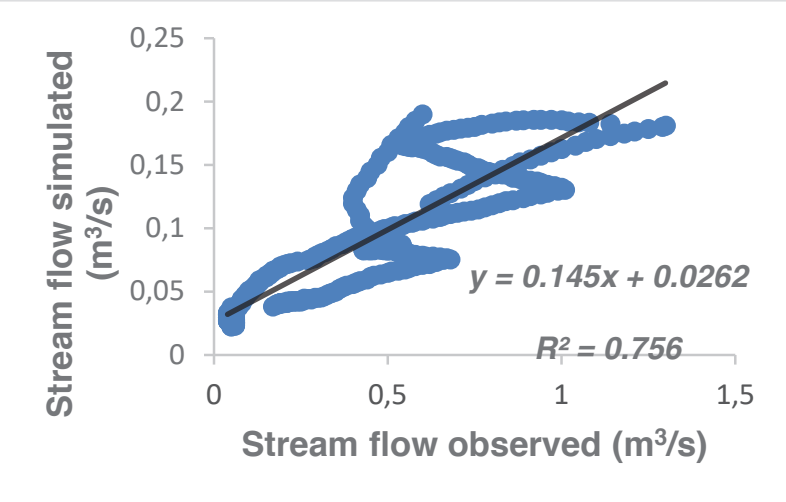

Fig. 7. Scatter plot of daily stream flow for calibration period (2001).

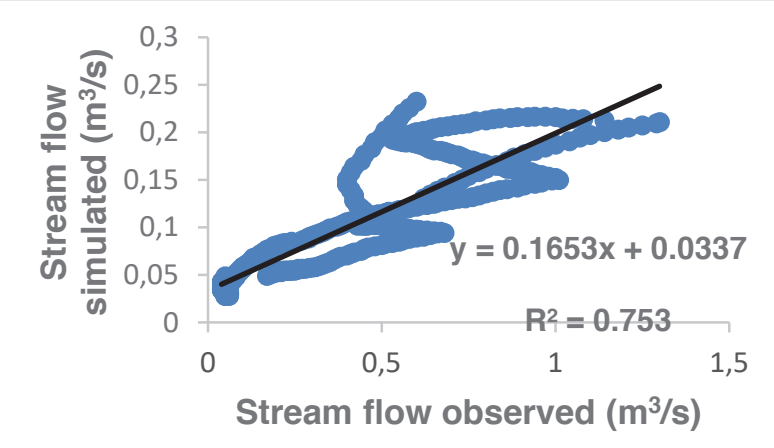

Fig. 8. Scatter plot of daily stream flow for validation period (2001).

\subsection{Sediment yield}

After calibrating and validating the model using measured daily flows, which found a strong correlation between what is simulated and what is measured. SWAT also allowed the quantification of annual soil losses per tonne and per hectare for each sub-basin and the identification of the most eroded and water-erosion areas (Fig. 9).

Soil losses vary from 0.064 t.ha ${ }^{-1}$.year ${ }^{-1}$ in sub-basin $\mathrm{n}^{\circ} 5$ to 96.62 t.ha $^{-1}$.year ${ }^{-1}$ in sub-basin $\mathrm{n}^{\circ} 32$, with an

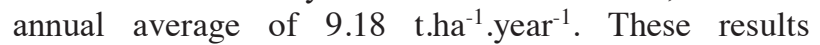
correspond to the results found by [18] (from 5 to 10 t.ha ${ }^{-1}$.year ${ }^{-1}$ ) for the High Atlas region of Morocco. According to figure $n^{\circ} 9$, the most eroded sub-basins are located on the sides of the Wadi of Ourika, the deforested land and the rangelands. Thus, these results remain consistent with the sedimentation surveys carried out on the profile of six reservoirs in various watersheds in Morocco, by the regional activity centre for the priority action programme [2], which revealed that water erosion varies from 2 to 59 t.ha $^{-1}$.year ${ }^{-1}$.

In the present study area, water erosion is mainly due to physical factors such as the very high climate variability characterized by frequent periods of drought and heavy rainfall; the presence of highly erodible soils due to their weak structure, lack of depth and absence of organic matter; and the uneven relief with steep slopes and very diverse landscapes. Socio-economic factors include the crisis of traditional agriculture with the consequent abandonment of land and degradation of soil and water conservation structures; the considerable loss of forests and natural vegetation; the overgrazing of rangelands, which has a particularly marked effect on the environment in a semi-arid climate; and the overexploitation of agricultural land.

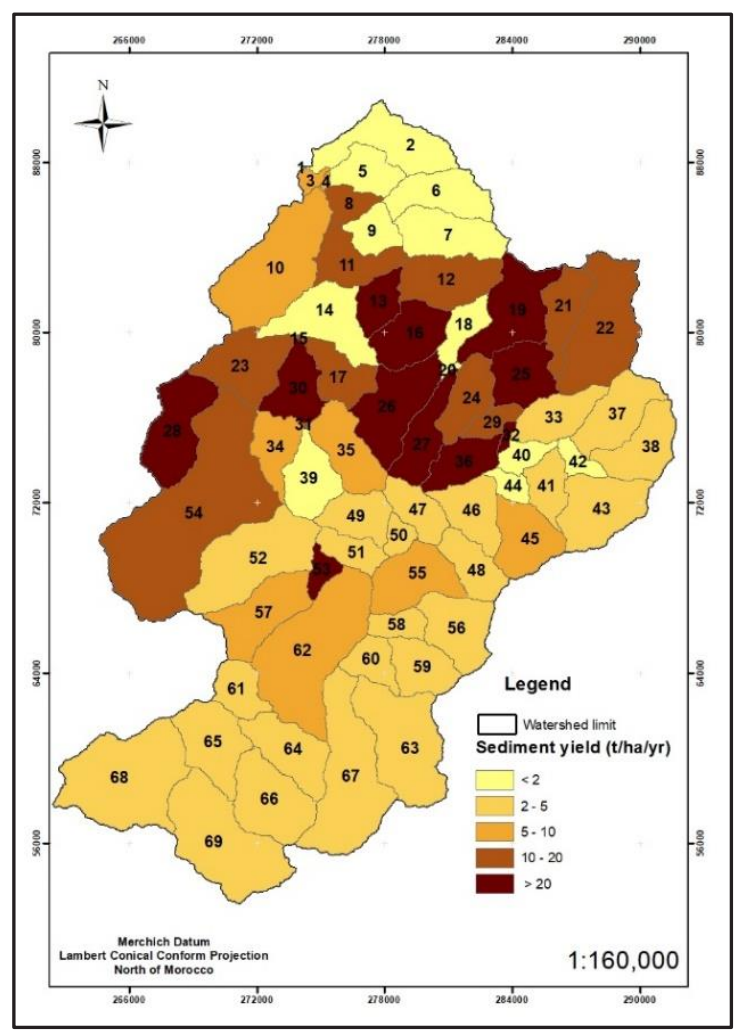

Fig. 9. Soil losses map of the Ourika watershed.

\section{Conclusion}

Erosion has very significant effects on the environment and the economy. It leads to a loss of soil productivity and reduced agricultural yields on the affected land. It also has considerable effects outside the directly affected land: increased sedimentation in streams and reservoirs that compromises water quality and the drainage capacity of watercourses. Both types of effects - local and external - have a significant negative impact on the water cycle and decrease the natural capacity of the land to regulate rivers in a region where water is a critical factor limiting socio-economic development. In order to study the causes and consequences of soil erosion, it is important to stress the high degree of integration and interrelationship between physical phenomena and the socio-economic context. Erosion control plans have, for the most part, focused on the symptoms rather than on the actual causes of this phenomenon. They have attempted to address directly the problems of overfarming, over-grazing, deforestation, etc. without addressing the socio-economic pressures that cause these symptoms [19].

It should be noted that, in all these processes, the phenomenon of erosion intervenes as a mechanism, but is also an indicator of the sustainability and good socio- 
economic integration of the coastal areas and the higher areas of the Mediterranean watersheds. The planning and design of mitigation measures is based on the concept of watershed restoration and management, i.e. on an integrated analysis of the basin's land resources and its degree of degradation as a basis for formulating a proposal for sustainable land use from the point of view of soil and water protection [20].

\section{References}

1. High Commission for Water and Forests and the Fight Against Desertification. Forest and water in a context of climate change, watershed management in Morocco, an unavoidable territorial approach, Morocco: pp. 8 (2016)

2. PAP/CAR: Regional Activity Centre for the Priority Action Programme in collaboration with FAO. Guidelines for mapping and measuring water erosion processes in Mediterranean coastal areas, Split, Croatie: pp. 2 (1998)

3. J. G. Arnold, P. M. Allen, Automated methods for estimating baseflow and groundwater recharge from streamflow records. J. American Water Resources. Assoc. 35 (2): pp. 411-424 (1999)

4. High Commission for Water and Forests and the Fight against Desertification. Ourika Forest Management Study: Preliminary study: pp. 54 (2002)

5. E. A. Elalaoui, M. E. Saidi, Simulation and spatialization of flood risk in an anthropized valley. The case of Ourika (High Atlas, Morocco): pp. 212214 (2014)

6. M. Modeste, A. Khattabi, N. Mhamdi, H. Zhang, Mapping Water Erosion Risks Using the Revised Universal Equation of Soil Losses, Remote Sensing and GIS in the Ourika Watershed (High Atlas, Morocco): pp. 280-281 (2016)

7. P. W. Gassman, M. R. Reyes, C. H. Green, J. G. Arnold, The Soil and Water Assessment Tool: Historical development, applications, and future directions. Transactions of the ASABE 50 (4): pp. 1211-1250 (2007)

8. J. Renaud, J. Poulenard, Implementation of the SWAT agri-environmental model on the Mercube watershed (Haute Savoie): Towards a modelling of phosphorus transfers. pp. 74. DESS report Jean Monnet-ENISE University (2004)

9. S. L. Neitsh, J. G. Arnold, J. R. Kiniry, K. W King, Soil and water assessment tool theoretical documentation-version 2005. Soil and water research laboratory, agricultural research service. Temple: US Department of Agriculture (2005)

10. K. C. Abbaspour, M. Vejdani, S. Haghighat, SWATCUP Calibration and uncertainty programs for SWAT. In MODSIM 2007 International Congress on Modelling and Simulation, Modelling and Simulation Society of Australia and New Zealand: pp. 1603- 1609 (2007)

11. F. Nachtergaele, H. van Velthuizen, L. Verelst, N. Batjes, K. Dijkshoorn, V. van Engelen, G. Fischer,
A. Jones, L. Montanarella, M. Petri, S. Prieler, X. Shi, E. Teixeira, D. Wiberg, The harmonized world soil database. 19th World Congress of Soil Science, Soil Solutions for a Changing World (2010)

12. D. N. Moriasi, J. G. Arnold, M. W. Van Liew, R. L. Bingner, R. D. Harmel, T. L. Veith, Model evaluation guideline for systematic quantification of accuracy in watershed simulation. Transactions of the ASABE, 50 (3): pp. 885-900 (2007)

13. S. Ferrant, F. Oehler, P. Durand, L. Ruiz, J. SalmonMonviola, E. Justes, P. Dugast, A. Probst, J. L. Probst, J. M. Sanchez-Perez, Understanding nitrogen transfer dynamics in a small agricultural catchment: Comparison of a distributed (TNT2) and a semi distributed (SWAT) modeling approaches. Journal of Hydrology 406 (1-2): pp. 1-15 (2011)

14. J. G. Arnold, D. N. Moriasi, P. W. Gassman, K. C. Abbaspour, M. J. White, R. Srinivasan, C. Santhi, R. D. Harmel, A. van Griensven, M. W. Van Liew, N. Kannan, M. K. Jha, SWAT: model use, calibration, and validation. Transactions of the ASABE: pp. 1491-1508 (2012)

15. C. Oeurng, S. Sauvage, J. M. Sánchez-Pérez, Assessment of hydrology, sediment and particulate organic carbon yield in a large agricultural catchment using the SWAT model. Journal of Hydrology 401 (3-4): pp. 145-153 (2011)

16. S. Kumar, V. Merwade, Impact of watershed subdivision and soil data resolution on swat model calibration and parameter uncertainty. Journal of the American Water Resources Association 45 (5): pp. 1179-1196 (2009)

17. D. N. Moriasi, M. W. Gitau, N. Pai, P. Daggupati, Hydrologic and Water Quality Models: Performance Measures and Evaluation Criteria. Transactions of the ASABE, 58 (6). pp. 1763-1785. doi:10.13031/trans.58.10715 (2015)

18. M. Ghanam, TS4 Management of Land. TS4.5 Desertification in Morocco - Which control strategy? 2nd FIG Regional Conference Marrakech, Morocco (2003)

19. G. Lean, Down to earth. A simplified guide to the Convention to combat desertification. The Centre for our common future, Geneva. pp. 32 (1995)

20. L. Rojo Serrano, Programs of national agencies for mitigation of desertification in Spain. European Union Concerted Action on Mediterranean Desertification. King's College, London. pp. 31 (1996) 